\title{
EVALUACIÓN DE UN PROGRAMA DE ACOMPAÑAMIENTO EN LOS PROCESOS DE LECTURA Y ESCRITURA A ESTUDIANTES SORDOS
}

\section{EVALUATION OF A PROGRAM OF SUPPORT TO DEAF STUDENTS IN THE PROCESSES OF READING AND WRITING}

\author{
Ligia Ochoa, Ana Cristina Gómez, Martha Lucía Osorno*
}

\begin{abstract}
Resumen
Entre los estudiantes sordos que ingresan a la Universidad Nacional para realizar una carrera profesional se encuentran aquellos que tienen como lengua materna la lengua de señas. Generalmente, ellos tienen un dominio incipiente del español escrito. En este documento se presenta el proceso investigativo y el acompañamiento pedagógico realizado a dos estudiantes de la Universidad Nacional con limitaciones auditivas. El objetivo principal fue mejorar sus procesos de lectura y escritura en español. Para verificar el cumplimiento de los objetivos se diseñó y aplicó una prueba de suficiencia de lectura y escritura en lengua española.
\end{abstract}

Palabras clave: Español, prueba de lengua, segundas lenguas.

\section{Abstract}

Among deaf students who are admitted to the National University for a career, are those who have sign language as their mother tongue. Usually, they have an incipient command of written Spanish. This document presents the investigative process and the pedagogical accompaniment to two students of the National University with hearing impediments. The main objective was to improve their processes of reading and writing in Spanish. To verify the fulfillment of the objectives, a test of sufficiency of reading and writing in Spanish was designed and applied.

Keywords: Spanish, language test, second languages, auditory limitation

\section{Antecedentes}

En obediencia a la Constitución Política de Colombia que exige que todas las poblaciones tengan acceso a la educación, la Universidad Nacional de Colombia ha incorporado dentro de su normativa el desarrollo de programas tendientes a mejorar las condiciones para que las comunidades más vulnerables, como indígenas, afros, mejores bachilleres de municipios pobres, mejores bachilleres y poblaciones de fronteras, se beneficien de la educación superior. Debido a la ausencia de políticas institucionales en torno a la inclusión universitaria de las personas en situación de discapacidad, desde hace aproximadamente 8 años, en el marco de un proyecto liderado por la Maestría en Discapacidad e Inclusión Social (2004), se pretende ofrecer las condiciones ade-

Artículo recibido: 10/10/2012 Aprobado: 06/05/2013

* Universidad Nacional de Colombia. Email: lochoas@unal.edu.co 
cuadas para el desarrollo de la prueba de admisión de aspirantes en situación de discapacidad y en equiparación de oportunidades con otros. Dicha actividad ha sido respaldada por la Dirección Nacional de Admisiones.

Posteriormente, se promueven acciones para garantizar la permanencia de los estudiantes en los programas de pregrado y postgrado que presentan algún tipo de limitación auditiva, visual, cognitiva, en la movilidad o con procesos de salud mental. A partir del año 2010, las actividades propias de la permanencia son asumidas por la Dirección de Bienestar Universitario y se le da una proyección nacional a través de sus respectivas direcciones en sedes y facultades. Este proceso se formaliza con la aprobación del Acuerdo 036 de 2012 sobre la inclusión de personas con discapacidad.

En relación con los aspirantes sordos usuarios de la lengua de señas, desde hace 4 años se han hecho esfuerzos por adaptar la prueba de ingreso de la población sorda a la lengua de señas. Actualmente se presenta en formato DVD. Así lo describe Osorno y Vargas (2011):

El trabajo se inició en el año 2004 con la identificación de las dificultades para la presentación de la prueba por personas sordas. Inicialmente se tenía como apoyo dos intérpretes para responder los requerimientos de un grupo de sordos. En el año 2009 se empezó a realizar la grabación de la prueba en LSC la cual ha tenido muy buena acogida entre los jóvenes sordos ya que mejoró considerablemente las condiciones de acceso y autonomía de la persona sorda en equiparación con los demás aspirantes. En el año 2010 se empieza un trabajo en todas las sedes de la Universidad, se cuenta con un examen grabado en LSC, lo cual brinda autonomía en el manejo de la prueba. Así mismo se ha tenido la experiencia con población sordo-ciega y la realización de los ajustes pertinentes a la prueba en video [...] Como parte de los apoyos se realizan talleres de formación en torno a la prueba: tipo de preguntas, uso de la herramienta tecnológica, familiarización con vocabulario de las preguntas; formación de docentes acompañantes, espacios accesibles, servicio de interpretación (2011, p. 85).

A pesar de los ajustes desarrollados a la prueba, la gran mayoría de los aspirantes sordos manifiesta tener serias dificultades al enfrentarse a los textos del examen. Algunos de estos problemas son el desconocimiento del léxico porque lo consideran muy especializado, la com- prensión y análisis de textos, los procesos de inferencia y deducción, la comprensión de las preguntas y uso de conectores. Así mismo, se han evidenciado en algunos de ellos debilidades en cuanto al uso de la lengua de señas: hay distorsión o cambio de las configuraciones manuales de las señas, uso inadecuado de la lengua, cambios en el significado y desconocimiento del léxico, todo ello dificulta la comprensión.

De otra parte, los estudiantes sordos ingresan a la universidad con bajos niveles académicos, pobre desarrollo de las competencias comunicativas tanto en la lengua de señas como en la lengua española y poca motivación hacia el lenguaje escrito. Posiblemente ocurre esto debido a una mala experiencia didáctica o porque tienen una percepción negativa de sí mismos. Algunas de estas dificultades fueron señaladas en la presentación "La inclusión de las personas sordas en la Universidad Nacional de Colombia" (2011).

Además, debe tenerse en cuenta que los procesos de adquisición/aprendizaje de la lengua española, en etapas previas a la universidad, se dan en contextos complejos, ya que muchos de los docentes no son bilingües, no conocen o no manejan metodologías para la enseñanza de esta lengua a niños y jóvenes sordos, no saben cómo afrontar la complejidad de los procesos de interpretación y traducción a la lengua de señas de los contenidos curriculares, entre otros.

De otra parte, la inclusión del estudiante sordo a las aulas regulares resulta problemática pues muchas instituciones buscan oralizarlo, lo que genera problemas de todo tipo. Afortunadamente, también hay esfuerzos importantes a nivel nacional e internacional para brindar una educación bilingüe a los sordos. Véase, por ejemplo el trabajo de Lissi, Svartholm, y González (2012) o el de Muiños y García (2000).

\section{Breves consideraciones teóricas}

La lengua es definida como un instrumento de interacción social, usada con el objetivo primordial de establecer relaciones de comunicación entre hablantes y destinatarios (Dik, 1997, p. 5).

Desde este modelo, el aprendizaje de una lengua y su evaluación supone el uso efectivo en situaciones comunicativas lo más auténticas posibles, semejantes a las interacciones en las que participan los hablantes na- 
tivos. Por tal motivo es necesario asumir los actos comunicativos desde una perspectiva discursiva, es decir, desde el punto de vista textual, social y cognitivo.

Es necesario, además, atender los niveles morfosintáctico, semántico y pragmático de la lengua, al momento de estudiar y evaluarla. Estos niveles deben contribuir al desarrollo de la competencia comunicativa, específicamente en los procesos de producción escrita y comprensión lectora.

El desarrollo y evaluación de estos procesos solo es posible si realmente los actos comunicativos están inscritos en un contexto comunicativo y cumplen una función similar a la que tienen en una sociedad como la hispanohablante. Se trata, entonces, de comprender y producir textos coherentes y funcionales.

A continuación se desarrollan tres tópicos esenciales para el desarrollo de los procesos de comprensión y producción de textos:

\section{El procesamiento lingüístico}

Como lo señala Igoa y García Albea (1999), hay una estrecha relación entre la comprensión y la producción. Por una parte, quien produce un texto lo hace pensando en un receptor específico, pero a la vez él también es receptor de su propio mensaje. Por otra parte, hay una especie de "solapamiento" entre los procesos de comprensión y producción; por ejemplo, la tarea del lector consiste en recuperar un mensaje a partir de una secuencia de letras (descodificación), mientras que el escritor hace un proceso inverso: traduce en letras el mensaje 0 su intención comunicativa (codificación).

Para producir un texto el emisor debe realizar una serie de procesos que conduzcan a la transmisión del mensaje deseado. Inicialmente, el emisor construirá el mensaje que desea transmitir y decidirá el contexto comunicativo en el que ha de actuar su producción; así mismo, decidirá su intención comunicativa, el tipo de discurso y el código en el que desea transmitir su mensaje de acuerdo con sus marcos de conocimiento, sus intereses y motivaciones, su sistema de valores y su propósito. Luego construirá una macroestructura que dé cuenta del contenido semántico del texto y a la vez que organice secuencias amplias 0 inclusive todo el texto. Una macroestructura está formada por un conjunto de macroproposiciones, es decir, enunciados que sintetizan o cubren varias proposiciones, que reflejan los temas 0 asuntos más generales e importantes del discurso (coherencia global) y las ideas centrales. La función de las macroproposiciones es anunciar o resumir de manera parcial las microproposiciones que se desarrollarán en el texto.

Una vez que tenga el "mapa" global del texto, empezará a desarrollar cada proposición hasta la producción lineal del texto, es decir que irá desde la macroproposición hasta las relaciones microestructurales entre las proposiciones y sus elementos constitutivos: oraciones, frases, palabras, entre otros. En este nivel aparecen los procesos de codificación léxica, gramatical y fonológica, si es necesario

La producción de secuencias de proposiciones de un texto posee un carácter cíclico: se registra una serie de proposiciones, se interrelacionan (formando un hecho), luego se acepta una nueva serie de proposiciones $y$, de ser posible, se liga con la serie anterior. Este proceso cíclico tiene como objeto unir información nueva con información ya conocida.

Del mismo modo disponemos también de modelos para la situación comunicativa propiamente dicha, que incluyen representaciones acerca de los demás participantes y el contexto comunicativo: qué creencias generales y específicas pueden darse por descontento a fin de que dicha creencia sea más aceptable por parte del oyente/lector.

El emisor debe decidir qué información debe presentar y cuál puede omitir porque la presupone en la memoria de sus interlocutores. Debe presentar la información de tal manera que el receptor active sus marcos de conocimiento y establezca las conexiones necesarias para dotar de significado al enunciado. Es preciso establecer lazos entre las informaciones de un texto y los conocimientos con los que contamos. El mayor conocimiento lleva a más relaciones, a un mayor valor estructural del texto y en fin, a una comprensión más profunda.

\section{La escritura como proceso}

De acuerdo con los planteamientos de la psicolingüística, el escritor realiza seis grandes procesos al momento de escribir: asegurar el contenido de lo que va a comunicar, planear el texto, elaborar una primera versión, corregirla, socializarla y editarla.

Según Gimeno et al. y Alonso Mateos (1985), citados por Cassany (1993), hay dos tipos de exigencias. En el 
primero están aquellas de alto nivel o superiores relacionadas con la composición del texto, como la discriminación entre información relevante e irrelevante, la planificación de la estructura del texto, creación y desarrollo de ideas, búsqueda de un lenguaje compartido con el lector, etc. El segundo tipo es de bajo nivel y apunta a los procesos más básicos y mecánicos, como hacer la caligrafía clara, dejar los espacios necesarios entre palabra y palabra y aplicar correctamente las reglas gramaticales y ortográficas.

Estos procesos se entrecruzan y aparecen en muchas ocasiones simultáneamente. Por ejemplo, la corrección puede empezar desde la planeación, pues un escritor continuamente está corrigiendo su texto y compartiéndolo con otros para ver su efecto. Se trata por tanto de un conjunto caracterizado por ser un "continuum de actividad de producción textual, un extenso y complejo proceso en el que están incluidas dichas operaciones" (Albadalejo, 1991, p. 61).

Sin embargo, por razones didácticas, es necesaria la separación de dichas operaciones, como una serie ordenada en la que los aspectos de cada una son delimitados y especificados, sin desconocer las íntimas relaciones entre ellas. Por ejemplo, es esencial asegurar los contenidos a través de cualquier medio: una visita, una investigación, una charla, un video, una canción, un libro, un debate, etc., antes de empezar a planear el texto. Con esta primera operación se busca que el escritor se apropie del conocimiento que le permita producir su texto y adquiera la competencia "conceptual" que le posibilita construir el referente que desea.

En la búsqueda del conocimiento necesario para la producción textual, el escritor puede recurrir a su memoria, a la experiencia directa con los objetos de conocimiento (la realidad misma), a imágenes, a los libros 0 a la interacción con otros.

La planeación se realiza teniendo en cuenta el contenido, la estructura del texto y el lector. El plan es como un resumen sumamente escueto; por lo general, no incluye ni siquiera frases sino conceptos sintetizadores de diversas secciones 0 apartados. En relación con la estructura, el escritor decide qué tipo de texto va a producir, cuáles son las partes que lo constituirán y qué relaciones hay entre ellas.

El escritor de un texto debe tener claro el tema sobre el que escribe y la forma en que lo va a presentar, pero esto no basta. La otra reflexión se refiere al lector: el autor tiene en cuenta los intereses y valoraciones del lector, sus conocimientos previos, sus posibilidades de comprensión, su posible aceptación o rechazo y adapta su argumentación a todo ello. Todas sus reacciones dependen, naturalmente, del contenido.

En consecuencia, el escritor experimentado oscila constantemente entre reflexiones de contenido y reflexiones pragmáticas. El que carece de experiencia suele olvidar al lector y pensar solo en el contenido y en su propio propósito.

Cuando se planea ya se está escribiendo. El escritor empieza a escribir cuando decide qué quiere transmitir y qué actitud determinada desea de su lector. Por tal motivo elige un tipo especial de texto.

Posteriormente, se escribe lo que se ha planeado con anterioridad. Es la primera versión del texto sobre la cual se va a trabajar después. Luego viene el mejoramiento del primer escrito. Los escritores profesionales rara vez esperan que sus textos queden bien en un primer intento. Generalmente, redactan varios borradores antes de quedar satisfechos.

Es necesario trabajar esta etapa con mucho cuidado pues lo más difícil del proceso de escritura es aprender a corregir los propios escritos. Esto solo se consigue a través de un esfuerzo continuo y constante.

Es recomendable que el escritor empiece por una lectura rápida para tener una visión de conjunto. Luego, debe realizar una lectura detenida para identificar qué dice el texto y qué quisiera, como autor, que dijera. Así podrá prever cómo reaccionará el lector, cómo quisiera que reaccionara, etc., y con base en ello, realice posteriormente las correcciones necesarias para transformar las ideas sueltas, aumentar o quitar información, reestructurar el texto, revisar la relación entre los párrafos, aclarar las partes oscuras, completar las ideas, modificar el orden de los párrafos, evitar las repeticiones, revisar las palabras sobre las cuales tiene dudas, utilizar el diccionario, etc. Luego, tendrá que realizar una tercera lectura, esta vez en voz alta para darse cuenta de cómo suena lo que ha escrito.

Las correcciones se hacen a todos los niveles: el texto en su conjunto, las partes, el párrafo, las oraciones, etc. También se observará desde los distintos aspectos de la 
lengua: pragmático, sintáctico, semántico y morfológico. Además, son necesarias múltiples operaciones en el plan $y$ en el correspondiente texto. Es recomendable que la ortografía se deje para el final.

Posteriormente, es recomendable que el escritor comparta con un lector su texto, con el fin de que su reacción le oriente hacia los puntos débiles del escrito. El autor tiene así la oportunidad de averiguar cómo incide su texto sobre el lector. Si los textos redactados proyectan situaciones reales, el escritor recibirá de las personas 0 las instancias a las que se ha dirigido unas respuestas breves y prácticas

No es conveniente que en la revisión se trabaje simultáneamente todos los niveles del texto porque puede ocurrir que no se vea nada de lo que hay que cambiar. Es importante construir una matriz de corrección que permita evaluar y mejorar los textos.

\section{La lectura: una fuente de información}

La lectura es esencialmente una forma de conocimiento, un medio de obtener información, un instrumento para conocer la realidad, para ampliar el mundo de los individuos y a la vez para producir nuevo conocimiento.

Es muy importante que los alumnos lean, por ejemplo, en el marco de un proyecto con una pregunta de investigación, de manera que la lectura ayude a obtener algunas respuestas. La pregunta hace posible que todos centren la atención en el mismo aspecto y asegura la motivación a la lectura.

En este proceso resulta muy valioso comparar un texto con otros similares o contrapuestos. La semejanza se puede referir a la temática o a diversos rasgos formales. Estas comparaciones posibilitan multitud de actividades escolares: trabajo individual, discusiones en grupo, diálogo en clase, confrontaciones detalladas, tentativas de explicación para las diferencias encontradas, búsqueda de otros textos similares, juicios comparativos, etc. En la elaboración de rasgos comunes se llega a diversas clases de textos, dentro de los cuales resulta posible también establecer diferenciaciones. Una de las comparaciones más fructíferas consiste en comparar el texto que los mismos alumnos construyeron después de un proceso de conocimiento con textos de otros autores; por ejemplo, comparar la descripción de una flor realizada por los alumnos con una descripción de un texto o con una ilustración de otro libro.
El hecho de que un texto sea confrontado con la observación propia y con la imagen científica del objeto, no solo llama la atención de los alumnos sobre la peculiaridad del escrito, sino que agudiza su mirada sobre los aciertos y los puntos débiles de la exposición del autor. También se puede comparar con el conocimiento que hemos adquirido en otros grados o que hemos adquirido en la vida.

Aebli (1988) considera que al leer, el alumno aprende constantemente en dos planos: en el plano del contenido y en el plano metodológico. Esto significa que, quien lee extrae del texto las informaciones específicas sobre un objeto de conocimiento determinado y a su vez adquiere la técnica de leer.

Los estudios modernos sobre lectura ponen gran énfasis en este plano metodológico. Se piensa que más que leer un texto específico es función de la escuela darle al estudiante las herramientas que le permitan leer en su vida diaria y cuando ya no sea estudiante. Estas herramientas se traducen en un conjunto de procedimientos para acercarse a un texto.

En consecuencia, es muy importante el tratamiento que se le hace a un texto, pues no solo asegura el nivel de comprensión sino que «comunica» un método (modo, forma) de leer y esto supone una manera de acercarse al conocimiento. La responsabilidad al enseñar a leer es grande: puede transmitir un acercamiento favorable a los textos y promover una actitud continua de conocer, de seguir leyendo.

De igual manera, Aebli considera que el tratamiento de los contenidos y métodos en un texto se debe realizar, desde tres puntos de vista diferentes:

a. El intelectual-estructural: hacer presente de un modo claro el contenido del texto, es decir, comprender las interconexiones en el texto y poner en claro la estructura de las relaciones entre las cosas.

b. El motivacional-emocional: despertar las emociones que mueven al autor y despertar en el lector sentimientos y sensaciones.

c. El axiológico o correspondiente a los valores: la lectura permite reflexionar acerca de los valores de una sociedad en relación con múltiples aspectos. 
Es recomendable que se lea primero en silencio el texto, solo después de esto, si es necesario, se le puede pedir a algún estudiante que lo lea en voz alta. No es conveniente que se pida leer en voz alta sin una preparación previa. En la lectura improvisada juegan para muchos estudiantes un papel perturbador de la emoción y la tensión, y por esto, aparecen como malos lectores muchos estudiantes, cuando quizá no se les ha preparado para ello.

\section{Metodología}

El trabajo se diseñó en dos fases: 1. Acompañamiento en los procesos de lectura y escritura académica y diseño y aplicación de una prueba de español. A continuación se hace referencia a cada una de estas fases.

\section{Acompañamiento a los procesos de lectura y escritura académica}

El apoyo a la permanencia y el acompañamiento a los procesos de comprensión y producción de textos se realizó a través de una estrategia múltiple: se ofreció a los estudiantes sordos el servicio de intérprete de lengua de señas en clases, monitorías particulares, flexibilidad curricular, talleres de expresión oral y escrita, clases personalizadas de español, apoyo en asignaturas de gran complejidad y apoyo para la desarrollo del trabajo de grado, bajo la guía de un tutor y específicamente en lo que tiene que ver con el proceso de redacción del documento.

Hubo también un trabajo importante a nivel de los docentes y directivos de los programas, ya que fue necesario crear conciencia acerca de las condiciones personales y académicas del estudiante sordo, la elaboración de materiales específicos para ellos e investigaciones en torno a esta problemática. De otra parte, el programa de Bienestar de la Facultad de Ciencias Humanas, el Comité asesor de la carrera de lingüística, el Comité asesor de la Maestría de discapacidad y el Centro de la Comunicación Humana acompañaron el proceso educativo y apoyaron toda iniciativa en aras de mejorar sus competencias comunicativas ${ }^{1}$.

En relación con los procesos de lectura y escritura, el énfasis estuvo en la comprensión y producción de textos académicos, es decir, propios de la carrera de lingüística aunque inicialmente se partió de referentes personales y cercanos al estudiante con actividades como la autobiografía, la familia o el grupo de amigos. Una de las dificultades de los estudiantes al escribir tiene con ver con la cantidad de información que manejan sobre un tema. Sus marcos de conocimiento son limitados a propósito de temáticas especializadas y por ello, es un error metodológico pedir a los estudiantes que escriban sobre temas que les son desconocidos, sin una preparación previa que les conduzca a adquirir el conocimiento necesario para llevar a cabo el proceso escrito. Sin este primer paso el segundo es imposible, por lo tanto es injusto decir que nuestros alumnos no pueden escribir cuando lo que pasa es que no poseen el bagaje conceptual para hacerlo. Para ello es necesario pensar en una metodología que posibilite el acercamiento de los estudiantes a los tópicos de manera activa e indagadora, y promueva experiencias de investigación y construcción de conocimiento, experiencias que solo los profesores de una disciplina pueden ofrecer.

Se trabajaron los procesos de lectura y escritura con la perspectiva de proceso y no de producto: lo que supuso considerarlas como procesos cognitivos que implican unas etapas y tiempos, y circunscribir los escritos a un contexto determinado y a unas funciones sociales específicas. Así mismo, se concibió la lectura principalmente como una fuente de información.

\section{Una prueba de español para los estudiantes sordos ${ }^{2}$}

Para evaluar el nivel de desempeño y como requisito que establece la Universidad de una segunda lengua como condición para el egreso en el último semestre de la carrera, se elaboró y aplicó una prueba de español. Se decidió hacer una prueba específica dado que las pruebas internacionales, como la del Instituto Cervantes, evalúan las 4 competencias comunicativas, ya que están pensadas para extranjeros. De igual manera, son elaboradas por españoles en la variedad lingüística española, lo que genera un ruido al examinado.

La evaluación de dominio o proficiencia mide el nivel de desempeño que tiene el evaluado en relación con lo que se quiere medir. Para la elaboración de la prueba se consultó el Marco Común Europeo de Referencia para

1. Al respecto véase el trabajo de Baquero, Beltrán y Santos (2008) y Baquero, Romero y Sánchez (2010).

2. La prueba fue aplicada solo a un estudiante. 
las Lenguas (MCER). Este marco ofrece una base común para desarrollar y evaluar programas, con lo cual posibilita equiparaciones en todos los sentidos: objetivos, contenidos, metodología y evaluación, de manera que fomente la cooperación internacional en el campo de las lenguas modernas. MCER es una fuente valiosa de información para la elaboración de programas, orientaciones curriculares, diseño de exámenes y manuales, etc. Describe también niveles de dominio discriminados en seis niveles: A1, A2, B1, B2, C1, C2 donde se señala lo que puede hacer el estudiante en cada nivel.

Para el caso de esta prueba de dominio se optó por el nivel B1.

La prueba tenía dos partes: en una primera se evaluó la comprensión lectora y en la segunda se evaluó la producción textual.

Para la elaboración del cuestionario de comprensión, el grupo gestor decidió hacer preguntas de dos tipos: literales, es decir, preguntas que se responden con la información explícita que aparece en el texto, y preguntas inferenciales. Para estas últimas se espera que el lector elabore una serie de deducciones a partir de la información que le ofrece el texto y de sus conocimientos previos. Se procuró que las preguntas se ajustaran al nivel requerido y a la población a la que se iba a aplicar: queríamos que no fueran demasiado sencillas, porque se menospreciaría las potencialidades de los examinados, ni demasiado complejas, lo que podría generar un bloqueo en el estudiante.

En total se hicieron 10 preguntas: cinco de selección múltiple y cinco con única respuesta.

Para la selección de los textos se tuvo en cuenta el campo disciplinar del examinado (lingüística) y el hecho de que pertenece a la comunidad sorda. Por lo tanto, se escogieron dos textos: uno de lingüística, específicamente de análisis del discurso y otro en el que una persona sorda narra el proceso por el que pasó en las instituciones educativas donde se formó. Este último texto nos sirvió, sobre todo, como pretexto para incursionar en la producción escrita con dos requerimientos: en uno se pide hacer un resumen del texto y en el segundo se solicita al examinado contar su experiencia como estudiante sordo de la Universidad Nacional de Colombia.

No se hizo un pilotaje de la prueba y la aplicación puede considerarse como un primer intento de hacer una prueba que siga los estándares internacionales de construcción de pruebas. Se trata de una especie de prueba piloto que nos da luces acerca de lo que se puede y debe indagar sobre comprensión y producción de textos en esta población y la forma de medirlo.

Para la evaluación de la comprensión lectora se asignó a cada pregunta un valor de 5 puntos, para un total de 50 .

Para la evaluación del resumen (10 puntos) se tuvo en cuenta los siguientes aspectos:

a. Presentación de las ideas principales del texto.

b. Los problemas de cohesión no afectan el sentido global del texto.

c. La información presentada es fiel a la original.

En relación con la escritura se acordó evaluar básicamente la coherencia del texto. De acuerdo con ello, los criterios que se emplearon fueron:

a. El texto responde al requerimiento hecho.

b. Hay una idea global o macroestructura.

c. Los problemas de cohesión no afectan el sentido global del texto.

El componente de comprensión tuvo un valor de 60 puntos y el de producción de 40.

El estudiante contó con dos horas para responder el examen: este tiempo es el que se determina para la prueba que hace la universidad para mostrar suficiencia en lengua inglesa.

\section{Resultados}

Los resultados de la prueba muestran que el estudiante mejoró sus procesos de comprensión y producción textual, lo que evidencia la efectividad del apoyo. Se respondió con cierta adecuación a las tareas solicitadas y los textos tienen una organización aceptable (hay título, párrafos y conciencia de la estructura de un texto).

A pesar de estos logros, en relación con la lectura, el estudiante respondió mejor a las preguntas literales que 
inferenciales y mucho mejor a las preguntas cerradas que al resumen. Estos resultados son los esperados pues muestran que a medida que se hace más compleja la tarea, aparecen más problemas. Por ejemplo, resumir es un proceso complejo que implica tres subprocesos: comprender el texto base, parafrasearlo en las propias palabras sin tergiversar las ideas del autor y cifrarlo en las normas del código escrito. En los resúmenes se detectan ideas falsas; es difícil saber si fue por falta de comprensión o porque no se expresaron adecuadamente, es decir, no se sabe si el problema es a nivel del significado 0 del significante.

Veamos ahora los problemas encontrados a nivel de escritura:

Los textos presentan problemas de orden gramatical, semántico y ortotipográfico. En relación con el primero, el mayor problema es el inadecuado uso de los elementos de relación, como preposiciones, artículos y conjunciones: a veces no los pone ( ${ }^{\star} m i$ historia estudio en nacho). En otros casos utiliza los que no corresponden ( ${ }^{*} \mathrm{con}$ fin / en fin) o los incluye cuando no hay necesidad (espero que lograr en mi sueño/ espero lograr mi sueño). Se evidencia, también, vacilación entre el uso de la conjunción, el

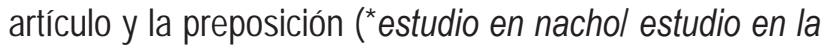
nacho, Paola puede comunicar con sus padres pero *una variedad de formas / en una variedad de formas).

De otra parte, hay serios problemas a nivel de la construcción verbal: ausencia de verbos cuando es necesario ( ${ }^{*} q u e$ debe examen (hacer)), estructuras verbales inadecuadas (espero que lograr, para puede, ya acostumbre estudie, terminar y apoya, tiene alejar), empleo de sustantivo en vez de verbo ( ${ }^{*} e l l a$ da cuenta que comunicación con su expresión facial/ ella se da cuenta que se comunica con su expresión facial), presenta dificultad con los verbos reflexivos ( ${ }^{*}$ comunicar/ comunicarse) y con los verbos irregulares ("${ }^{*}$ pudo/puedo), y también tiene un manejo inadecuado de los tiempos verbales ("pues me paso a universidad/ cuando pasé a la universidad).

Hay, así mismo, elisión de elementos esenciales para la coherencia oracional (*un examen para los sordos como personas oyentes/ como se hace para las personas oyentes; también los sordos tienen proceso la adquisición/ también los sordos tienen un proceso de adquisición de la lengua; deben acceso a social/ deben tener acceso a lo social). Esta elisión puede explicarse porque a veces se mantiene un registro oral ( ${ }^{*} \mathrm{Nacho}$ / Universidad Nacional de Colombia; continuación, como normal/ continué los estudios en forma normal). Este registro en ocasiones permite ciertas elisiones. Por último, los textos presentan problemas de concordancia (los niños... utiliza expresión facial; comunidad sordos esta marginados; pudo estudiar en universidad público).

A nivel semántico, el mayor problema es la imprecisión léxica. Por ejemplo, el empleo del verbo ser en vez de tener o viceversa, términos no españoles como el adjetivo oralidades en vez de orales, el uso de tender por tener, y limitar por enfrentarse con. Hay incomprensión de los términos en su contexto; por ejemplo, en vez de poner como sinónimo de resistirse contra ella la palabra oponerse, el estudiante señala sufrir, que si bien es un significado de este verbo, no lo es en el contexto trabajado.

A nivel ortotipográfico hay ausencia de acentos y, en ocasiones, empleo inadecuado de los signos de puntuación.

Si bien pragmáticamente se logra el objetivo de narrar una experiencia de vida, se hace de una manera muy general y tangencial, y en ocasiones no se posiciona adecuadamente al emisor: necesito/necesitamos (los sordos).

\section{Discusión y conclusiones}

Los resultados coinciden con los problemas reportados por Sales \& Sainz (2006) y por Hernández (2006). Los resultados muestran también que el estudiante responde mejor cuando se le pide hablar sobre su propia experiencia que cuando habla sobre temas ajenos a pesar de que conoce la situación. Esto muestra, como lo señala Cummins (1983), la estrecha relación que hay entre los procesos lingüísticos y los procesos complejos de pensamiento.

Si bien parece adecuado utilizar textos cercanos a los universos de los estudiantes y a sus disciplinas de estudio para desarrollar la comprensión y la producción textual, es necesario trabajar en la adquisición de competencias más complejas y académicas con esta población. Lo ideal es que el fortalecimiento de las competencias lingüísticas en ambas lenguas se dé desde los niveles educativos previos a su ingreso a la educación superior.

Es indispensable que el trabajo de la competencia comunicativa no se circunscriba a un solo espacio, como por ejemplo cursos especiales para esta población, sino que es necesario que todas las asignaturas contribuyan a 
este propósito. Sólo un trabajo continuo, en el que la lectura y escritura se desarrollen a través del currículo, permite el desarrollo de la competencia comunicativa.

De otra parte, solo es posible desarrollar los procesos de comprensión y producción de textos en un contexto dialogante. Solo cuando los profesores de un programa reconocen en el otro a un interlocutor válido, se ponen en su lugar y están dispuestos a aprender de él, pueden contribuir realmente a su desarrollo.

La interrelación entre las habilidades de lectura y escritura desarrolla los procesos comunicativos en uno y otro sentido. La escritura, en tanto práctica sobre la que se puede volver una y otra vez, aporta herramientas tangibles que posteriormente se pueden extrapolar a la comprensión; por ejemplo, se puede leer para escribir y escribir para leer.

Así mismo, conviene avanzar en el planteamiento de propuestas de investigación y de formación docente que posibiliten resolver las diversas problemáticas e interrogantes que se presentan en el proceso enseñanza/ aprendizaje de la segunda lengua a los educandos sordos, que deriven en una mejor calidad de educación para esta población de tal forma que les permita optar por un mejor perfil profesional y por ende, un desempeño profesional exitoso. Es importante resaltar el papel crucial que tiene el profesorado en este proceso y es indispensable lograr que los docentes de las disciplinas interactúen adecuadamente con los estudiantes sordos.

\section{Referencias bibliográficas}

Aebli, H. Doce formas básicas de enseñar. Una didáctica basada en la psicología. Madrid: Narcea Ediciones, 1988. 1991.

Albadalejo, T. Retórica. Madrid: Editorial síntesis,

Baquero, S., Beltrán, M., \& Santos, D. Adaptaciones pedagógicas para estudiantes sordos en la Universidad Nacional de Colombia: reflexiones curriculares. Revista Colombiana de Educación 54(2008):1-10

Baquero, S., Flórez, R., Sánchez, L. Desarrollo de habilidades en el español escrito en personas sordas universitarias: estudio de caso. Forma y Función 23(2010):33-71.
Cassany, D. Describir el escribir. Barcelona: Paidós, 1993.

Cummins, J. Interdependencia lingüística y desarrollo educativo de los niños bilingües. Infancia y Aprendizaje 21(1983):37-62.

Dik, S. The Theory of Functional Grammar. Part 1: The Structure of the Clause. Berlín, New York: Mouton de Gruyter. 1997.

Hernández, M. El español hablado en Cuba. Importancia de su estudio en la Carrera de Educación Especial. ISPEJV. FORUM de Ciencias Pedagógicas. Santiago de Cuba, 2006.

Igoa, J. \& García, J. Unidades de planificación y niveles de procesamiento en la producción del lenguaje. En F. Cuetos \& M. Vega. Psicolingüística del español. España: Trotta. (1999):373-398.

Primer Encuentro Distrital de Sordos Universitarios La inclusión de las personas sordas en la Universidad Nacional de Colombia. Bogotá. (CD), 2011.

Lissi, M., Svartholm, K. \& González, M. El Enfoque Bilingüe en la Educación de Sordos: sus implicaciones para la enseñanza y aprendizaje de la lengua escrita. Estudios Pedagógicos 38(2)(2012):299-320. Recuperado de http:/ /www.scielo.cl/scielo.php?script= sci_arttext\&pid=S071807052012000200019\&lng= es\&nrm=iso>. ISSN 07180705. http://dx.doi.org/10.4067/S0718-07052012000200019.

Marco Común Europeo de Referencia para las Lenguas (MCER). Madrid: Instituto Cervantes. (Traducción), 2002.

Muiños, M. y García, R. Educación bilingüe en las personas sordas. En: A. Caiñeiras (Ed.) $O$ reto da innovación na Educación Especial (pp. 347-352). Santiago de Compostela: Instituto de Ciencias de Educación, 2000.

Osorno, M \& Vargas, D. Síntesis presentaciones del Primer encuentro Distrital de sordos universitarios realizado en agosto 2011. Bogotá: Universidad Nacional de Colombia, 2011.

Sales, L. \& Sainz M. Metodología para la enseñanza de segundas lenguas a personas sordas. VIII Congreso Latinoamericano de Educación bilingüe para sordos, 2006. 